\title{
Concepts and clinical use of ultra-long basal insulin
}

Freddy Goldberg Eliaschewitz ${ }^{*}$ and Tânia Barreto ${ }^{2}$

\begin{abstract}
Diabetes mellitus (DM) is a public health issue, affecting around 382 million people worldwide. In order to achieve glycemic goals, insulin therapy is the frontline therapy for type 1 DM patients; for patients with type 2 DM, use of insulin therapy is an option as initial or add-on therapy for those not achieving glycemic control. Despite insulin therapy developments seen in the last decades, several barriers remain for insulin initiation and optimal maintenance in clinical practice. Fear of hypoglycemia, weight gain, pain associated with blood testing and injection-related pain are the most cited reasons for not starting insulin therapy. However, new generation of basal insulin formulations, with longer length of action, have shown the capability of providing adequate glycemic control with lower risk of hypoglycemia.
\end{abstract}

Keywords: Diabetes mellitus, Ultra-long basal insulin, Glycemic control, Hypoglycemia

\section{Insulin therapy development}

Diabetes mellitus (DM) affects around 382 million people worldwide, with type $2 \mathrm{DM}$ accounting for $85-95 \%$ of all cases [1]. Diabetes may be managed with tight glycemic control, aiming to achieve glycosylated hemoglobin (A1C) levels below or around $7 \%$, considering even more stringent goals (such as $<6.5 \%$ ) for selected patients. This can be achieved without significant adverse events, as hypoglycemia [2], due to the relation of lower A1C levels with fewer microvascular complications [3-6]. Insulin therapy is recommended as frontline therapy for type 1 DM patients; for patients with type $2 \mathrm{DM}$, use of insulin is an option as initial or add-on therapy for those not achieving glycemic control with initial oral drugs [2]. Currently, only in the United States, around 6 million people aged $\geq 18$ years with DM use insulin therapy (28.7\% of the DM patients population in this age in the country) [7].

Insulin was first used in diabetic patients in the 1920s [8], but the first commercial preparations contained numerous impurities and relevant potency variation [9]. In the 1930s protamine zinc insulin was developed, resulting in delayed absorption and longer duration of

\footnotetext{
*Correspondence: freddy.g@uol.com.br

1 CPClin Clinical Research Center, 91, Goiás St., São Paulo, SP 01244-030, Brazil

Full list of author information is available at the end of the article
}

action, thus reducing the number of doses needed for insulin replacement-but still with considerable instability [10]. In 1946, neutral protamine Hagedorn (NPH) insulin was produced and could be pre-mixed with soluble insulin, becoming the main basal insulin throughout the 20th century [10].

In the early 1980s, the development of human insulin innovated with refinement of insulin therapy, especially regarding basal insulin [9]. New long-acting insulin analogues, glargine and detemir, showed less day-to-day variability and longer duration of action, thus allowing once-daily dosing $[11,12]$.

The search for an ideal insulin therapy regimen still continues, aiming to provide optimal glycemic control with limited adverse events and improved convenience to the patient [13] (Fig. 1).

\section{Pharmacokinetic and pharmacodynamics profiles of insulin therapy}

Overall development of insulin aims to decrease patients' hypoglycemia episodes and improve pharmacokinetics (PK)/pharmacodynamics (PD) profile, by mimicking as close as possible the normal insulin release [14]. Variability of PK profile among insulins directly influences PD effects, increasing the probability of hypoglycemia episodes due to unpredictability of insulin peaks. In addition, temporal separation of insulin PK and PD profiles 


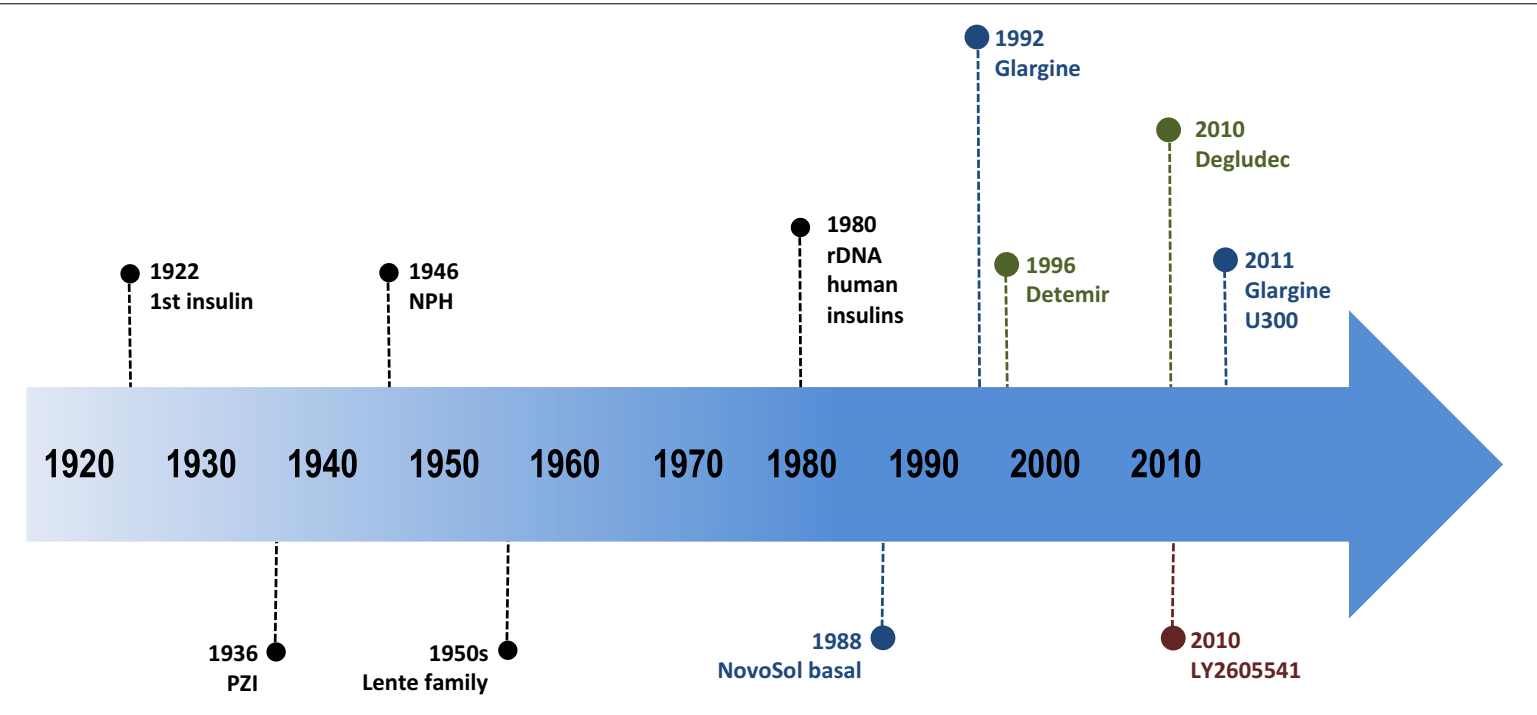

Change in isoelectric point towards neutral pH

Acylation of insulin with fatty acids C14-C16

PEGylated insulin

Fig. 1 Timeline for insulin developments. Adapted from Owens [10]

is affected by several factors, thus PK and PD profiles of insulin may be studied separately, each with its specific measurement $[15,16]$.

In order to minimize hypoglycemia or hyperglycemia episodes, insulin analogues with different PK/PD profiles were developed, including basal and ultra-long basal insulins. Unfortunately, current insulin options do not fulfill the main requirements for ideal basal insulin: flat PD profile, with low hypoglycemia risk, $24 \mathrm{~h}$ duration, and low interindividual variability (Fig. 2).

Insulin NPH has a delayed absorption profile, with a peak in $4.5 \mathrm{~h}$ after administration. Besides, insulin $\mathrm{NPH}$ action doesn't last for $24 \mathrm{~h}$, so usually it has to be administered at least twice a day. Furthermore, NPH

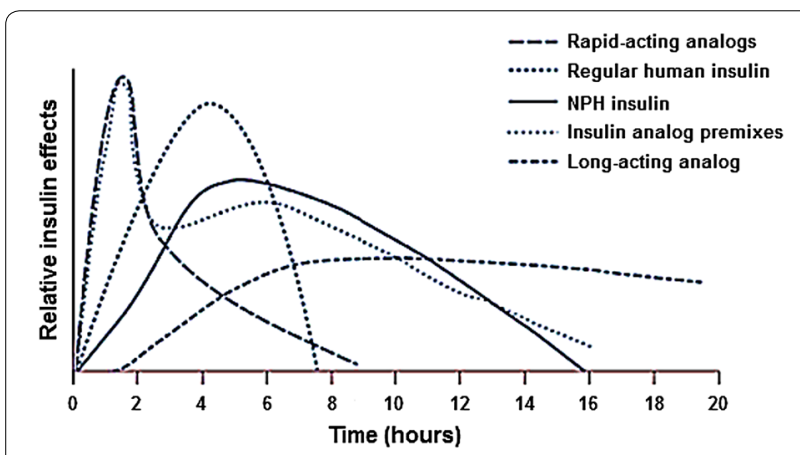

Fig. 2 Comparison between the action time profiles of different insulins. Adapted from: Tibaldi [59] treatment has high inter and intraindividual variability [17]. Thus, other insulins were developed to improve PK/PD profile.

In 2000, insulin glargine was the first long-acting insulin analogue available. After subcutaneous injection, glargine precipitates in the subcutaneous tissue delaying the absorption [18]. Insulin glargine has one amino acid substituted in the A chain and two in the B chain: this modifies the isoelectric point of the protein, decreasing its solubility at physiologic $\mathrm{pH}$. Due to its delayed absorption, glargine also demonstrates a flatter PK/PD profile, with longer duration and less variability when compared to NPH [17].

Insulin detemir is another bioengineered insulin developed by removing a threonine and acylating a lysine residue with 14-carbon fatty acid, both in the B chain. It has a PK/PD profile very similar to glargine (flatter PK/PD profile, approximately 24 -h duration and low variability), although insulin glargine is slightly more effective and stable in glycemic control [19].

However, both glargine and detemir still do not completely mimic physiological insulin secretion. When administered in high doses, both show a peak on PK/ PD profile [20]; also, a low dose may not be enough to cover a 24-h period and there is still interindividual variability [21]. To attempt to overcome this issue, ultra-long insulins were developed, being degludec, LY2605541 and glargine U300 the most promising. 
Insulin degludec is a modified B chain analogue that, like other insulin, forms hexamers and di-hexamers when injected subcutaneously. As the slow diffusion of zinc molecule, present in the hexamer, occurs, the insulin monomer is finally absorbed. Compared with insulin glargine and detemir, degludec promotes flatter PK/ PD profiles, decreasing the number of confirmed hypoglycemia episodes [22]. Insulin degludec has a half-life superior to $25 \mathrm{~h}$, with action exceeding $42 \mathrm{~h}$, however the most studied schedule in clinical trials is based on once daily doses.

Insulin LY2605541 (or PEGylated Lispro) has polyethylene glycol (PEG) polymer chain attached in the molecule structure. PEGylation slows LY2605541 subcutaneous absorption and decrease its renal clearance, promoting the creation of a peakless PK/PD profile and increasing LY2605541 half-life. LY2605541 presents a PK/PD profile very similar to insulin degludec, with mean half-life of $35 \mathrm{~h}$ [23, 24] but, differently from degludec, LY2605541 causes weight loss and hepatic lipid accumulation in both type 1 [25] and type 2 DM [24]. The mechanisms of hepatic lipid accumulation are unknown but led to the discontinuation of this insulin.

The most recent clinical approach for ultra-long insulin is glargine $\mathrm{U} 300(300 \mathrm{U} / \mathrm{ml})$. The analogue has the same mechanism to extent absorption as insulin glargine. When administered subcutaneously, U300 forms subcutaneous depot with smaller surface area, creating a prolonged release that results in a flatter PK/PD profile than in glargine U100. Furthermore, exposure to U300 is more evenly distributed (Fig. 3) [26], and glucose control remains for $36 \mathrm{~h}$ [27], resulting in decreased hypoglycemic episodes (overall and nocturnal) in insulin-based [28] or insulin combined with oral antihyperglycemic drugs therapy [29]. U300 also demonstrated reduced variability and a tendency to decrease weight gain compared with glargine U100.

It should be highlighted that insulin therapy should always try to mimic the physiological insulin release, thus longer half-life insulin is not always the best choice. As an example, ultralente insulin has a mean duration of $20 \mathrm{~h}$, which is superior to $14 \mathrm{~h}$ of insulin NPH [17]. However, this insulin presents higher interindividual variability, higher incidence of hypoglycemia episodes and worse glucose control when compared with NPH $[17,26]$. Due to its inferior clinical profile, ultralente was withdrawn from the market in 2005.

Ultra-long insulins offer efficacy and safety, with less pharmacodynamics variability and intraindividual variability, and duration of action over $24 \mathrm{~h}$. Among these insulins, both U300 and degludec can be used as basal and basal-bolus therapy, in type 1 and type $2 \mathrm{DM}$, offering the advantage of flexibility. This means that healthcare professionals and diabetic patients don't need to be rigid about the timing of injections.

\section{Clinical trials evaluating ultra-long-acting insulin formulations}

\section{Insulin degludec for type 1 DM}

BEGIN was an open-label, treat-to-target, non-inferiority, multicentric trial assessing adult patients with type $1 \mathrm{DM}$ who had been treated with basal-bolus insulin for at least 1 year $(70 \%$ receiving insulin glargine and $19 \%$ receiving insulin detemir at screening) [23]. In total, 626 participants were randomized in a 3:1 ratio to receive once-daily insulin degludec $(100 \mathrm{U} / \mathrm{mL} ; 3 \mathrm{~mL})$ or insulin glargine $(100 \mathrm{U} / \mathrm{mL} ; 3 \mathrm{~mL})$, both in combination with mealtime insulin aspart. Primary objective was
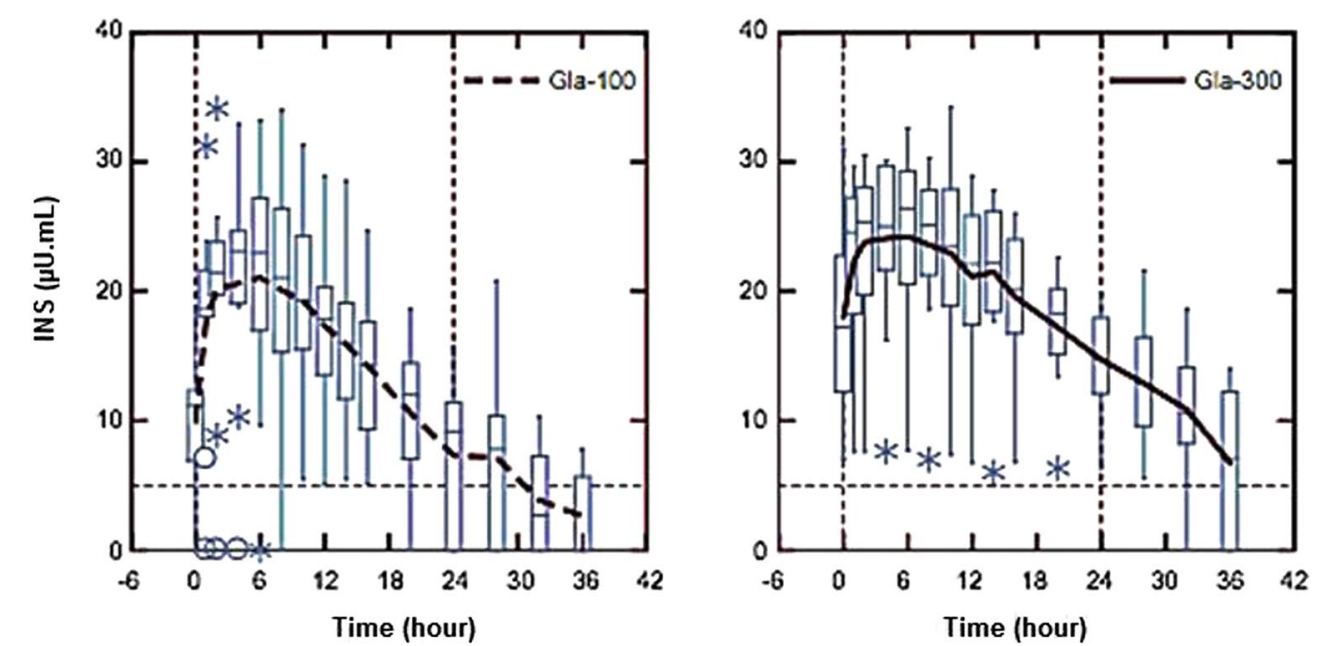

Fig. 3 Concentration of insulin glargine U300 versus U100 over time in steady. Adapted from Becker et al. [26] 
to confirm non-inferiority of degludec over glargine in reducing A1C levels after 52 weeks of treatment [23]. Insulin degludec demonstrated to be non-inferior, with a reduction in A1C levels by $0.4 \%$ points versus $0.39 \%$ points with glargine (difference of $-0.01 \%$ points; $95 \%$ CI $-0.14-0.11 ; \mathrm{p}<0.0001$ for non-inferiority). Rates of overall confirmed hypoglycemia were similar in both groups, but the rate of confirmed nocturnal hypoglycemia was $25 \%$ lower with degludec (4.41 versus 5.86 episodes/patient-year of exposure; relative risk 0.75; CI $95 \% 0.59-0.96$ ). No differences in weight gain or in other adverse events were observed between study groups [23]. A 52-week extension of the BEGIN trial corroborated the benefits of degludec on confirmed nocturnal hypoglycemia, with a sustained event reduction of $25 \%$ (CI $95 \%$ from 5 to $41 \%$ ), without significant differences in efficacy or in other adverse events [30]. These data evidence the efficacy and safety of degludec, as well as its non-inferiority in relation to insulin glargine.

A subsequent trial (BEGIN: Flex T1) investigated efficacy and safety of insulin degludec once daily, but varying the injection time [31]. This was an open-label, treat-totarget, non-inferiority trial comparing insulin degludec $(100 \mathrm{U} / \mathrm{mL})$ in a fixed schedule (with minimum $8 \mathrm{~h}$ and maximum $40 \mathrm{~h}$ between doses) with degludec (100 U/ $\mathrm{mL} ; 3 \mathrm{~mL})$ or glargine $(100 \mathrm{U} / \mathrm{mL} ; 3 \mathrm{~mL})$ given at the same time every day, once daily, with mealtime insulin aspart. After 26 weeks of treatment, mean A1C and fasting plasma glucose levels were reduced similarly in the 3 groups. Insulin degludec in the flexible schedule achieved non-inferiority and significantly reduced confirmed nocturnal hypoglycemia [31]. Also, the study highlighted the advantage of the long duration of degludec in offering more flexibility in terms of injection timings.

\section{Insulin degludec for type $2 \mathrm{DM}$}

BEGIN basal-bolus type 2 study was an open-label treatto-target, non-inferiority trial, performed at 123 sites in 12 countries. The study enrolled adult patients with type $2 \mathrm{DM}$ who had been treated with any insulin regimen for at least 3 months with or without oral antidiabetic drugs and had A1C concentrations of 7.0-10.0\% [32]. This trial randomized 1006 patients (3:1) to receive once-daily insulin degludec $(100 \mathrm{U} / \mathrm{mL} ; 3 \mathrm{~mL})$ or glargine $(100 \mathrm{U} /$ $\mathrm{mL} ; 3 \mathrm{~mL}$ ), in combination with mealtime insulin aspart, with or without prescribed metformin, pioglitazone or both. The primary objective was to confirm the noninferiority of degludec over glargine in reducing $\mathrm{A} 1 \mathrm{C}$ levels. After 1 year, A1C decreased by $1.1 \%$ in the degludec group and $1.2 \%$ in the glargine group (estimated difference degludec-glargine: $0.08 \%$; $95 \% \mathrm{CI}-0.05$ to 0.21 ), confirming its non-inferiority [32]. Rates of overall confirmed hypoglycemia were lower with degludec (11.2 versus 13.6 episodes/patient-year of exposure; estimated ratio 0.82 ; $95 \%$ CI $0.69-0.99$ ), as well as rates of confirmed nocturnal hypoglycemia (1.4 versus 1.8 episodes/ patient-year of exposure; estimated ratio $0.75 ; 95 \%$ CI $0.58-0.99$ ). Rates of severe hypoglycemia were too low to assess differences, and adverse events occurred in a similar rate in both groups [32]. A 26-week extension showed that degludec maintained similar improvement in glycemic control compared with glargine, with fewer hypoglycemic episodes ( $24 \%$ overall reduction and $31 \%$ confirmed nocturnal episodes reduction) [33].

Another 1-year large phase 3 trial (BEGIN Once Long) randomized 1030 patients (3:1) with type $2 \mathrm{DM}$, insulin-naïve, inadequately controlled with oral antidiabetic drugs (A1C 7-10\%) to receive insulin degludec or glargine once daily, both combined with metformin [34]. Insulin degludec showed similar rates of glycemic control but, again, with reduced risk of confirmed nocturnal hypoglycemia as well as of severe adverse events [34]. The 52-week extension of BEGIN Once Long trial showed sustained benefits of insulin degludec in hypoglycemic episodes [35].

Flexible schedule of administration of insulin degludec has also been studied in type 2 DM patients. BEGIN Flex trial assessed 687 patients ( $41.8 \%$ already receiving insulin therapy) randomized to receive degludec in a flexible once-daily schedule (with prespecified rotating doses of 8-40 h intervals), degludec once daily at the main evening meal, or glargine [36]. In this trial, no differences between groups were reported on glycemic control, hypoglycemia or adverse events, suggesting that daily injection time of insulin degludec can vary without compromising efficacy [36].

\section{Insulin glargine 300 units $/ \mathrm{mL}$ for type $1 \mathrm{DM}$}

EDITION 4 trial is a randomized, phase 3a, open-label study recently published (2015). The study randomized 549 patients $(1: 1: 1: 1)$ to receive once-daily insulin glargine $300 \mathrm{U}$ or $100 \mathrm{U}$, in the morning or evening, while continuing mealtime insulin. Participants had diabetes duration of 21 years and HbA1c level of $8.1 \%$ [37]. Overall, glargine $300 \mathrm{U}$ was non-inferior over glargine $100 \mathrm{U}$ for the primary endpoint (HbA1c change from baseline), with reductions of 0.40 versus $0.44 \%$, respectively (mean difference 0.04; CI $95 \%-0.10$ to $0.19 \%$ ). Event rates of confirmed or severe hypoglycemia $(\leq 3.9 \mathrm{mmol} / \mathrm{L})$ were similar in both groups while nocturnal hypoglycemia was lower in glargine $300 \mathrm{U}$ group during the first 8 weeks of the study [37]. Insulins or times of injection showed no differences in glycemic control, hypoglycemia or adverse events between groups. Glargine 300U led to a statistically significant lower weight gain (mean difference $-0.56 \mathrm{~kg}$; CI $95 \%-1.09$ to $-0.03 \mathrm{~kg}$ ) [37]. Also, 
the convenience of a once-daily injection and lower rates of hypoglycemia should convert into improvements in treatment satisfaction.

\section{Insulin glargine 300 units $/ \mathrm{mL}$ for type $2 \mathrm{DM}$}

EDITION 1 was a 6 -month multinational (conducted in 13 countries), open-label trial that assessed adult patients with type $2 \mathrm{DM}$ who were receiving basal-bolus insulin therapy (requiring $\geq 42$ units/day of basal insulin) for at least one year ( $57.4 \%$ with prior use of metformin; other oral antidiabetic therapies were not allowed) and with A1C levels $7.0-10.0 \%$. Participants $(n=807)$ were randomized to receive once-daily injections of insulin glargine $300 \mathrm{U}$ or $100 \mathrm{U}$ through 6 months [28]. Reduction in A1C levels (primary endpoint) was similar in both groups (mean change of $-0.83 \%$ for both groups), meeting the non-inferiority criterion. The main secondary endpoint was the percentage of patients with one or more confirmed or severe nocturnal hypoglycemia $(\leq 3.9 \mathrm{mmol} / \mathrm{L})$ reported between week 9 and month 6 and patients receiving glargine $300 \mathrm{U}$ achieved better results, with a $21 \%$ risk reduction (relative risk 0.79; $95 \%$ CI 0.67-0.93). Adverse events or treatment-emergent adverse events were equally distributed between the groups [28]. A preplanned 6-month extension showed sustained glycemic control and less hypoglycemia with glargine 300U [38]. A lower percentage of participants receiving insulin glargine $300 \mathrm{U}$ experienced confirmed or severe hypoglycemia (85.9 versus $91.5 \%$; $R R=0.94$; CI $95 \% 0.89-0.97$ ) and the annualized rate of documented symptomatic nocturnal hypoglycemia was lower in this group (1.8 versus 2.5 per participant-year; $R R=0.74$; CI $95 \% 0.56$ $0.97)$ [38].

EDITION 2 was a randomized phase 3 trial with a design similar to EDITION 1: it was a 6-month, openlabel trial conducted in 213 centers across 13 countries, analyzing adult patients with type $2 \mathrm{DM}$ who were receiving basal insulin therapy (requiring $\geq 42$ units/day of basal insulin) for at least 1 year and with A1C levels 7.0-10.0 \% [29]. This study differed from EDITION 1 because patients were not receiving mealtime rapid-acting insulin and they could receive other antidiabetic therapies, except sulphonylureas and glinides (in $94 \%$, oral therapy was metformin). Participants $(n=811)$ were randomized to receive once-daily injections of insulin glargine $300 \mathrm{U}$ or $100 \mathrm{U}$ in the study period. Primary endpoint was change in A1C levels from baseline to month 6 and the results were statistically similar in both groups (mean change of $-0.57 \%$ for glargine $300 \mathrm{U}$ and $-0.56 \%$ for glargine $100 \mathrm{U})$, meeting the non-inferiority criterion. The main secondary endpoint was the percentage of patients with one or more confirmed or severe nocturnal hypoglycemia event $(\leq 3.9 \mathrm{mmol} / \mathrm{L})$ reported between week 9 and month 6 and it was lower in patients receiving glargine $300 \mathrm{U}(21.6 \%)$ than glargine $100 \mathrm{U}(27.9 \%)$, with a risk reduction of $23 \%$ (relative risk of 0.77 ; $95 \%$ CI $0.61-$ 0.99). EDITION 2 participants continued in a 6-month safety extension in order to examine long-term outcomes [39]. Over 12 months, improved control of HbA1c was maintained in both treatment groups, and event rates/ participant-year of confirmed or severe nocturnal hypoglycemia were $37 \%$ lower with insulin glargine $300 \mathrm{U}$ (1.74 versus 2.77; $\mathrm{RR}=0.63$; CI $95 \% 0.42-0.96$ ) [39].

EDITION 3 is another multicentric randomized trial evaluating insulin glargine $300 \mathrm{U}$, but assessing insulin-naive adult patients with type $2 \mathrm{DM}$ on oral glucose-lowering drugs [40]. Participants $(\mathrm{n}=878)$ were randomized to receive once-daily injections of insulin glargine $300 \mathrm{U}$ or $100 \mathrm{U}$, throughout the 6-month study period, after discontinuing sulphonylureas and glinides. The primary endpoint was change in $\mathrm{A} 1 \mathrm{C}$ levels from baseline to month 6 and the results showed an equivalent reduction in both groups (mean change of $-1.42 \%$ for glargine $300 \mathrm{U}$ and $-1.46 \%$ for glargine $100 \mathrm{U}$; mean difference $0.04 \%$; CI $95 \%-0.09$ to $0.17 \%$ ), meeting the non-inferiority criterion. In this trial, non-inferiority was pre-defined as a difference $<0.4 \%$ in A1C levels between the treatment groups. The main secondary endpoint was the percentage of patients with one or more confirmed or severe nocturnal hypoglycemia event $(\leq 3.9 \mathrm{mmol} / \mathrm{L})$ reported between week 9 and month 6 and it was statistically similar in patients receiving glargine $300 \mathrm{U}(16 \%)$ or glargine 100U (17\%). When considering the whole 6-month treatment period, fewer patients receiving glargine $300 \mathrm{U}$ experienced such events (18 versus $24 \%$; $\mathrm{RR}=0.76$; CI $95 \% 0.59-0.99$ ) [40].

Flexible dosing intervals of insulin glargine 300U were also tested in type $2 \mathrm{DM}$ patients. Patients participating in EDITION $1(\mathrm{n}=109)$ and EDITION $2(\mathrm{n}=89)$ using glargine $300 \mathrm{U}$ were randomized, at month 6 , to continue the fixed regimen or move to flexible regimen, allowing between-injection intervals of $24 \pm 3 \mathrm{~h}$ on at least 2 days each week [41]. In the latter group, throughout this 3-month flexibility sub-study, only $50-60 \%$ of injections ranged $24 \pm 1 \mathrm{~h}$. HbA1c change was comparable in fixed versus flexible regimens and hypoglycemia events occurred equally between both groups, showing that glargine $300 \mathrm{U}$ provides flexibility to occasionally adapt the timing of insulin injections to individuals' daily changing lifestyle patterns [41].

\section{Barriers for insulin therapy implementation and unmet needs: emphasis in hypoglycemia}

Several barriers remain for insulin initiation and optimal maintenance in clinical practice, both at the patient and at the physician levels. Fear of hypoglycemia, weight 
gain, pain associated with blood testing and injectionrelated pain are the most cited reasons for not starting insulin therapy in type $2 \mathrm{DM}$ patients [42]. Also, patient perception that insulin therapy is complicated and time consuming can interfere with its timely initiation [43]. Adherence to insulin therapy, however, is more influenced by factors like health insurance patterns and being too busy $[44,45]$.

Fear of hypoglycemia impacts not only in the decision to start insulin therapy, but it may also jeopardize the adequacy of glycemic control. It has been reported that most physicians would treat patients without adequate glucose control in a more aggressively manner if not for concerns about hypoglycemia [45].

\section{Burden of hypoglycemia in patients with $\mathrm{dm}$ receiving insulin therapy}

Hypoglycemia is an important adverse event of DM therapy as it potentially impairs the patients' health-related quality of life while imposing other burdens $[17,18]$. Observational studies report that hypoglycemia occurs in up to 42.89 events/patient-year, in type $1 \mathrm{DM}$ patients, and in up to 16.36 events/patient-year in insulin-treated type $2 \mathrm{DM}$ patients $[46,47]$. Rates of severe hypoglycemia are approximately of 1.15 events/patient-year, and can reach 3.2 events/patient-year in type $1 \mathrm{DM}$ patients; in insulin-treated type $2 \mathrm{DM}$ patients, rates are 0.7 events/ patient-year [46, 47].

Nocturnal hypoglycemia, which occurs during sleep, is particularly dangerous since patients are unlikely to recognize symptoms or awake during an episode [48]. In the Diabetes Control and Complications Trial (DCCT), 43 and $55 \%$ of all hypoglycemic and severe hypoglycemic events reported, respectively, occurred during sleep [49].

A large web survey conducted in the US with 7.239 participants with type 2 DM (28.7\% treated with insulin) showed that hypoglycemia interfered with social activities, causing more absenteeism and decreasing overall work productivity, also impacting negatively on overall healthrelated quality of life [50]. Another survey, performed in US and Europe, attested that even non-severe hypoglycemic events cause major impairments on productivity, with productivity loss estimated from U\$ 15.26 to U\$ 93.47, representing 8.3 to $15.9 \mathrm{~h}$ of lost work time per month [51]. Also, a time trade-off utility study with DM patients receiving insulin therapy in US and Canada showed that non-severe hypoglycemic episodes led to deterioration in utility [52]. Further research has reported that patients with confirmed hypoglycemia episodes had significant impairment in health-related quality of life [53], greater mood disturbance and less work satisfaction [54].

Specific burden of nocturnal hypoglycemia has also been studied. A survey recruited DM patients in US,
Canada and in 7 European countries who experienced a non-severe nocturnal hypoglycemia event in the previous month [55]. The 2108 respondents $(32.8 \%$ with type 1 and $67.2 \%$ with type $2 \mathrm{DM} ; 74.2 \%$ receiving insulin therapy) reported that hypoglycemic episodes significantly affected sleep and next day functioning, with $60.7 \%$ stating a moderate to severe impact [55]. Another survey assessing 8286 patients in 5 countries (US, Canada, Germany, Sweden and United Kingdom) presented that living in a health state with nocturnal hypoglycemia is considered worse than living with daytime hypoglycemia [56]. Other studies also reported the detrimental impact of nocturnal hypoglycemia on quality of life, including impact on family members and cost-related factors [57].

The potential association of hypoglycemia with neurological impairment is also worrisome. A longitudinal study following 16,667 older patients with type $2 \mathrm{DM}$ (mean age: 65 years; $35 \%$ receiving insulin therapy) through 27 years showed an increased risk in dementia among patients with reported hypoglycemic episodes, with risks growing as the number of episodes increased [58].

Additionally, hypoglycemic episodes can lead patients to exhibit medication-avoidance behavior, with many reducing or even omitting insulin doses after an event, which may jeopardize glycemic control $[51,55,57]$.

\section{Conclusion}

Patients with DM benefit from a tight glycemic control strategy, which requires insulin therapy for type $1 \mathrm{DM}$ as well as for many patients with type $2 \mathrm{DM}$. Achieving adequate target levels of blood glucose, however, may lead to higher incidence of hypoglycemic episodes, including nocturnal events, which are associated with impairment in productivity and in health-related quality of life, and may also jeopardize cognition in older patients. Furthermore, hypoglycemia is considered a barrier for implementing more intensive therapies, which can reduce the chances of attaining optimal glucose control.

New generation of basal insulin formulations, with longer length of action, showed the capability of providing adequate glycemic control, in the same extent as insulin glargine, but with decreased risk of hypoglycemia, especially nocturnal episodes. Thus, they help fulfilling the need to adequate glycemic control with lower risks of hypoglycemic events.

The scientific grounds regarding ultra-long basal insulins provide possibilities of its adoption either as upfront therapy as well as, in scenarios with cost constraints, for patients already receiving long-acting insulins glargine or detemir but that have suffered from recurrent episodes of hypoglycemia. 


\section{Abbreviations}

Cl: confidence interval; DM: diabetes mellitus; GIR: glucose infusion rate; Gla-100: insulin glargine 100 U; Gla-300: insulin glargine 300 U; NPH: neutral protamine Hagedorn; PD: pharmacodynamics; PK: pharmacokinetics; RR: relative risk; T1DM: type 1 diabetes mellitus; T2DM: type 2 diabetes mellitus.

\section{Authors' contributions}

FGE conceived of the study, carried out the literature review, analyzed the data and drafted the manuscript. TB participated in the data analyzes, helped to draft the manuscript and reviewed the manuscript. All authors read and approved the final manuscript.

\section{Author details}

${ }^{1}$ CPClin Clinical Research Center, 91, Goiás St., São Paulo, SP 01244-030, Brazil. ${ }^{2}$ Sanofi's Medical Division, América Business Park-5200, Major Sylvio de Magalhães Padilha Av., Jd. Morumbi, São Paulo, SP 05693-000, Brazil.

\section{Acknowledgements}

The authors are grateful for the support of Dr. Luciano Paladini, Christiane Bueno and Guilherme Julian in the preparation of this manuscript, which was supported by a grant from Sanofi.

\section{Competing interests}

FGE is member of the scientific advisory board Sanofi. FGE delivers conferences for Merck Sharpe and Dome, Sanofi, Novo-Nordisk, and Eli Lilly. TB is Medical Manager at Sanofi's Medical Division.

Publication support was provided by Sanofi.

Received: 14 July 2015 Accepted: 23 December 2015

Published online: 06 January 2016

\section{References}

1. International Diabetes Federation IDF. IDF Diabetes Atlas - 6th edition. 6th ed. Brussels: IDF; 2013.

2. American Diabetes Association. Standards of medical care in diabetes-2014. Diabetes Care. 2014;37(Suppl 1):S14-80. doi:10.2337/ dc14-5014.

3. The Diabetes Control and Complications Trial Research Group. The effect of intensive treatment of diabetes on the development and progression of long-term complications in insulin-dependent diabetes mellitus. N Engl J Med. 1993;329(14):977-86. doi:10.1056/nejm199309303291401.

4. Intensive blood-glucose control with sulphonylureas or insulin compared with conventional treatment and risk of complications in patients with type 2 diabetes (UKPDS 33). UK Prospective Diabetes Study (UKPDS) Group. Lancet. 1998;352(9131):837-53.

5. Fullerton B, Jeitler K, Seitz M, Horvath K, Berghold A, Siebenhofer A. Intensive glucose control versus conventional glucose control for type 1 diabetes mellitus. Cochrane Database Syst Rev. 2014;2:CD009122. doi:10.1002/14651858.CD009122.pub2.

6. Hemmingsen B, Lund SS, Gluud C, Vaag A, Almdal TP, Hemmingsen C, et al. Targeting intensive glycaemic control versus targeting conventional glycaemic control for type 2 diabetes mellitus. Cochrane Database Syst Rev. 2013;11:CD008143. doi:10.1002/14651858.CD008143.pub3.

7. Kramer CK, Zinman B, Retnakaran R. Are metabolically healthy overweight and obesity benign conditions?: A systematic review and meta-analysis. Ann Intern Med. 2013;159(11):758-69. doi:10.7326/0003-4819-159-11-201312030-00008.

8. Rosenfeld L. Insulin: discovery and controversy. Clin Chem. 2002;48(12):2270-88.

9. Hirsch IB. Insulin analogues. N Engl J Med. 2005;352(2):174-83. doi:10.1056/NEJMra040832.

10. Owens DR, Matfin G, Monnier L. Basal insulin analogues in the management of diabetes mellitus: What progress have we made? Diabetes Metab Res Rev. 2014;30(2):104-19. doi:10.1002/dmrr.2469.

11. Swinnen SG, Simon AC, Holleman F, Hoekstra JB, Devries JH. Insulin detemir versus insulin glargine for type 2 diabetes mellitus. Cochrane Database Syst Rev. 2011;7:CD006383. doi:10.1002/14651858.CD006383. pub2.
12. Horvath K, Jeitler K, Berghold A, Ebrahim SH, Gratzer TW, Plank J, et al. Long-acting insulin analogues versus NPH insulin (human isophane insulin) for type 2 diabetes mellitus. Cochrane Database Syst Rev. 2007;2:CD005613. doi:10.1002/14651858.CD005613.pub3.

13. Unger J. Uncovering undetected hypoglycemic events. Diabetes Metab Syndr Obes. 2012;5:57-74. doi:10.2147/dmso.s29367.

14. Arnolds S, Kuglin B, Kapitza C, Heise T. How pharmacokinetic and pharmacodynamic principles pave the way for optimal basal insulin therapy in type 2 diabetes. Int J Clin Pract. 2010;64(10):1415-24. doi:10.1111/j.1742-1241.2010.02470.x.

15. Heinemann L, Chantelau EA, Starke AA. Pharmacokinetics and pharmacodynamics of subcutaneously administered U40 and U100 formulations of regular human insulin. Diabete Metab. 1992;18(1):21-4.

16. Heinemann L. Time-action profiles of insulin preparations. Mainz: Verlag Kirchheim + Co., GmbH; 2004

17. Lepore M, Pampanelli S, Fanelli C, Porcellati F, Bartocci L, Di Vincenzo A, et al. Pharmacokinetics and pharmacodynamics of subcutaneous injection of long-acting human insulin analog glargine, NPH insulin, and ultralente human insulin and continuous subcutaneous infusion of insulin lispro. Diabetes. 2000;49(12):2142-8.

18. Owens DR, Coates PA, Luzio SD, Tinbergen JP, Kurzhals R. Pharmacokinetics of 125l-labeled insulin glargine (HOE 901) in healthy men: comparison with NPH insulin and the influence of different subcutaneous injection sites. Diabetes Care. 2000;23(6):813-9.

19. Abe S, Inoue G, Yamada S, Irie J, Nojima H, Tsuyusaki K, et al. Two-way crossover comparison of insulin glargine and insulin detemir in basalbolus therapy using continuous glucose monitoring. Diabetes Metab Syndr Obes. 2011;4:283-8. doi:10.2147/DMSO.S21513.

20. Heise T, Pieber TR. Towards peakless, reproducible and long-acting insulins. An assessment of the basal analogues based on isoglycaemic clamp studies. Diabetes Obes Metab. 2007;9(5):648-59. doi:10.1111/j.1463-1326.2007.00756.x.

21. Ashwell SG, Gebbie J, Home PD. Twice-daily compared with once-daily insulin glargine in people with Type 1 diabetes using meal-time insulin aspart. Diabet Med. 2006;23(8):879-86. doi:10.1111/j.1464-5491.2006.01913.x.

22. Ratner RE, Gough SC, Mathieu C, Del Prato S, Bode B, Mersebach H, et al. Hypoglycaemia risk with insulin degludec compared with insulin glargine in type 2 and type 1 diabetes: a pre-planned meta-analysis of phase 3 trials. Diabetes Obes Metab. 2013;15(2):175-84. doi:10.1111/dom.12032.

23. Heller S, Buse J, Fisher M, Garg S, Marre M, Merker L, et al. Insulin degludec, an ultra-longacting basal insulin, versus insulin glargine in basal-bolus treatment with mealtime insulin aspart in type 1 diabetes (BEGIN Basal-Bolus Type 1): a phase 3, randomised, open-label, treat-totarget non-inferiority trial. Lancet. 2012;379(9825):1489-97. doi:10.1016/ S0140-6736(12)60204-9.

24. Bergenstal RM, Rosenstock J, Arakaki RF, Prince MJ, Qu Y, Sinha VP, et al. A randomized, controlled study of once-daily LY2605541, a novel long-acting basal insulin, versus insulin glargine in basal insulin-treated patients with type 2 diabetes. Diabetes Care. 2012;35(11):2140-7. doi:10.2337/ dc12-0060.

25. Rosenstock J, Bergenstal RM, Blevins TC, Morrow LA, Prince MJ, Qu Y, et al. Better glycemic control and weight loss with the novel longacting basal insulin LY2605541 compared with insulin glargine in type 1 diabetes: a randomized, crossover study. Diabetes Care. 2013;36(3):522-8. doi:10.2337/dc12-0067.

26. Becker RH, Dahmen R, Bergmann K, Lehmann A, Jax T, Heise T. New Insulin Glargine 300 Units.mL-1 Provides a More Even Activity Profile and Prolonged Glycemic Control at Steady State Compared With Insulin Glargine 100 Units.mL-1. Diabetes Care. 2015;38(4):637-43. doi:10.2337/ dc14-0006.

27. Tillner J, Bergmann K, Teichert L, Dahmen R, Heise T, Becker RHA. Euglycemic clamp profile of new insulin glargine $U 300$ formulation in patients with type 1 diabetes (T1DM) is different from glargine U100 (Abstract). Diabetes 2013. p. A920-P.

28. Riddle MC, Bolli GB, Ziemen M, Muehlen-Bartmer I, Bizet F, Home PD. New insulin glargine 300 units $/ \mathrm{mL}$ versus glargine 100 units $/ \mathrm{mL}$ in people with type 2 diabetes using basal and mealtime insulin: glucose control and hypoglycemia in a 6-month randomized controlled trial (EDITION 1). Diabetes Care. 2014;37(10):2755-62. doi:10.2337/dc14-0991. 
29. Yki-Jarvinen H, Bergenstal R, Ziemen M, Wardecki M, Muehlen-Bartmer I, Boelle E, et al. New Insulin Glargine 300 Units/mL Versus Glargine 100 Units/mL in People With Type 2 Diabetes Using Oral Agents and Basal Insulin: Glucose Control and Hypoglycemia in a 6-Month Randomized Controlled Trial (EDITION 2). Diabetes Care. 2014;37(12):3235-43. doi:10.2337/dc14-0990.

30. Bode BW, Buse JB, Fisher M, Garg SK, Marre M, Merker L, et al. Insulin degludec improves glycaemic control with lower nocturnal hypoglycaemia risk than insulin glargine in basal-bolus treatment with mealtime insulin aspart in Type 1 diabetes (BEGIN((R)) Basal-Bolus Type 1): 2-year results of a randomized clinical trial. Diabet Med. 2013;30(11):1293-7. doi:10.1111/dme.12243.

31. Mathieu C, Hollander P, Miranda-Palma B, Cooper J, Franek E, RussellJones $\mathrm{D}$, et al. Efficacy and safety of insulin degludec in a flexible dosing regimen vs insulin glargine in patients with type 1 diabetes (BEGIN: Flex T1): a 26-week randomized, treat-to-target trial with a 26-week extension. J Clin Endocrinol Metab. 2013;98(3):1154-62. doi:10.1210/jc.2012-3249.

32. Garber AJ, King AB, Del Prato S, Sreenan S, Balci MK, Munoz-Torres M, et al. Insulin degludec, an ultra-longacting basal insulin, versus insulin glargine in basal-bolus treatment with mealtime insulin aspart in type 2 diabetes (BEGIN Basal-Bolus Type 2): a phase 3, randomised, open-label, treat-totarget non-inferiority trial. Lancet. 2012;379(9825):1498-507. doi:10.1016/ s0140-6736(12)60205-0.

33. Hollander P, King AB, Del Prato S, Sreenan S, Balci MK, Munoz-Torres M, et al. Insulin degludec improves long-term glycaemic control similarly to insulin glargine but with fewer hypoglycaemic episodes in patients with advanced type 2 diabetes on basal-bolus insulin therapy. Diabetes Obes Metab. 2014. doi:10.1111/dom.12411.

34. Zinman B, Philis-Tsimikas A, Cariou B, Handelsman Y, Rodbard HW, Johansen $T$, et al. Insulin degludec versus insulin glargine in insulin-naive patients with type 2 diabetes: a 1-year, randomized, treat-to-target trial (BEGIN Once Long). Diabetes Care. 2012;35(12):2464-71. doi:10.2337/ dc12-1205.

35. Rodbard HW, Cariou B, Zinman B, Handelsman Y, Philis-Tsimikas A, Skjoth TV, et al. Comparison of insulin degludec with insulin glargine in insulinnaive subjects with Type 2 diabetes: a 2-year randomized, treat-to-target trial. Diabet Med. 2013;30(11):1298-304. doi:10.1111/dme.12303.

36. Meneghini L, Atkin SL, Gough SC, Raz I, Blonde L, Shestakova M, et al. The efficacy and safety of insulin degludec given in variable once-daily dosing intervals compared with insulin glargine and insulin degludec dosed at the same time daily: a 26-week, randomized, open-label, parallelgroup, treat-to-target trial in individuals with type 2 diabetes. Diabetes Care. 2013;36(4):858-64. doi:10.2337/dc12-1668.

37. Home PD, Bergenstal RM, Bolli GB, Ziemen M, Rojeski M, Espinasse M, et al. New Insulin Glargine 300 Units/mL Versus Glargine 100 Units/mL in People With Type 1 Diabetes: A Randomized, Phase 3a, Open-Label Clinical Trial (EDITION 4). Diabetes Care. 2015. doi:10.2337/dc15-0249.

38. Riddle MC, Yki-Järvinen H, Bolli GB, Ziemen M, Muehlen-Bartmer I, Cissokho $S$ et al. Sustained glycaemic control and less hypoglycaemia with new insulin glargine $300 \mathrm{U} / \mathrm{ml}$ vs $100 \mathrm{U} / \mathrm{ml}$ : 1-year results in type 2 diabetes with basal and mealtime insulin (EDITION 1). 50th European Association for the Study of Diabetes annual meeting; Vienna 2014.

39. Yki-Järvinen $H$, Bergenstal RM, Bolli GB, Ziemen M, Wardecki M, MuehlenBartmer I et al. Less nocturnal hypoglycaemia and weight gain with new insulin glargine $300 \mathrm{U} / \mathrm{ml}$ vs $100 \mathrm{U} / \mathrm{ml}$ : 1-year results in people with type 2 diabetes using basal insulin and OADs (EDITION 2). 50th European Association for the Study of Diabetes annual meeting; Vienna 2014.

40. Bolli GB, Riddle MC, Bergenstal RM, Ziemen M, Sestakauskas K, Goyeau $\mathrm{H}$, et al. New insulin glargine $300 \mathrm{U} / \mathrm{ml}$ compared with glargine $100 \mathrm{U} /$ $\mathrm{ml}$ in insulin-naive people with type 2 diabetes on oral glucose-lowering drugs: a randomized controlled trial (EDITION 3). Diabetes Obes Metab. 2015. doi:10.1111/dom.12438.

41. Jeandidier N, Riddle MC, Bolli GB, Home PD, Bergenstal RM, Ziemen M et al. New insulin glargine $300 \mathrm{U} / \mathrm{ml}$ : efficacy and safety of flexible vs fixed dosing intervals in people with type 2 diabetes mellitus. 50th European Association for the Study of Diabetes annual meeting; Vienna 2014.

42. Lau AN, Tang T, Halapy H, Thorpe K, Yu CH. Initiating insulin in patients with type 2 diabetes. CMAJ. 2012;184(7):767-76. doi:10.1503/ cmaj.110779.

43. Sorli C, Heile MK. Identifying and meeting the challenges of insulin therapy in type 2 diabetes. J Multidiscip Healthc. 2014;7:267-82. doi:10.2147/ jmdh.s64084

44. Davies MJ, Gagliardino JJ, Gray LJ, Khunti K, Mohan V, Hughes R. Realworld factors affecting adherence to insulin therapy in patients with Type 1 or Type 2 diabetes mellitus: a systematic review. Diabet Med. 2013;30(5):512-24. doi:10.1111/dme.12128.

45. Peyrot M, Barnett AH, Meneghini LF, Schumm-Draeger PM. Insulin adherence behaviours and barriers in the multinational Global Attitudes of Patients and Physicians in Insulin Therapy study. Diabet Med. 2012;29(5):682-9. doi:10.1111/j.1464-5491.2012.03605.x.

46. Donnelly LA, Morris AD, Frier BM, Ellis JD, Donnan PT, Durrant R, et al. Frequency and predictors of hypoglycaemia in Type 1 and insulin-treated Type 2 diabetes: a population-based study. Diabet Med. 2005;22(6):74955. doi:10.1111/j.1464-5491.2005.01501.x.

47. Risk of hypoglycaemia in types. 1 and 2 diabetes: effects of treatment modalities and their duration. Diabetologia. 2007;50(6):1140-7. doi:10.1007/s00125-007-0599-y.

48. Brunton SA. Nocturnal hypoglycemia: answering the challenge with long-acting insulin analogs. MedGenMed. 2007;9(2):38.

49. The DCCT Research Group. Epidemiology of severe hypoglycemia in the diabetes control and complications trial. Am J Med. 1991;90(4):450-9.

50. Lopez JM, Annunziata K, Bailey RA, Rupnow MF, Morisky DE. Impact of hypoglycemia on patients with type 2 diabetes mellitus and their quality of life, work productivity, and medication adherence. Patient Prefer Adherence. 2014:8:683-92. doi:10.2147/ppa.s58813.

51. Brod M, Christensen T, Thomsen TL, Bushnell DM. The impact of nonsevere hypoglycemic events on work productivity and diabetes management. Value Health. 2011;14(5):665-71. doi:10.1016/j.jval.2011.02.001.

52. Levy AR, Christensen TL, Johnson JA. Utility values for symptomatic nonsevere hypoglycaemia elicited from persons with and without diabetes in Canada and the United Kingdom. Health Qual Life Outcomes. 2008;6:73. doi:10.1186/1477-7525-6-73.

53. Williams SA, Shi L, Brenneman SK, Johnson JC, Wegner JC, Fonseca V. The burden of hypoglycemia on healthcare utilization, costs, and quality of life among type 2 diabetes mellitus patients. J Diabetes Complications. 2012;26(5):399-406. doi:10.1016/j.jdiacomp.2012.05.002.

54. UK Prospective Diabetes Study (UKPDS) Group. Quality of life in type 2 diabetic patients is affected by complications but not by intensive policies to improve blood glucose or blood pressure control (UKPDS 37). Diabetes Care. 1999;22(7):1125-36.

55. Brod M, Wolden M, Christensen T, Bushnell DM. A nine country study of the burden of non-severe nocturnal hypoglycaemic events on diabetes management and daily function. Diabetes Obes Metab. 2013;15(6):54657. doi:10.1111/dom.12070.

56. Evans M, Khunti K, Mamdani M, Galbo-Jorgensen CB, Gundgaard J, Bogelund $M$, et al. Health-related quality of life associated with daytime and nocturnal hypoglycaemic events: a time trade-off survey in five countries. Health Qual Life Outcomes. 2013;11:90. doi:10.1186/1477-7525-11-90.

57. Edelman SV, Blose JS. The Impact of Nocturnal Hypoglycemia on Clinical and Cost-Related Issues in Patients With Type 1 and Type 2 Diabetes. Diabetes Educ. 2014;40(3):269-79. doi:10.1177/0145721714529608.

58. Whitmer RA, Karter AJ, Yaffe K, Quesenberry CP Jr, Selby JV. Hypoglycemic episodes and risk of dementia in older patients with type 2 diabetes mellitus. JAMA. 2009;301(15):1565-72. doi:10.1001/jama.2009.460.

59. Tibaldi JM. Evolution of insulin development: focus on key parameters. Adv Ther. 2012:29(7):590-619. doi:10.1007/s12325-012-0034-8 